\title{
An Electrospray Ionization Mass Spectrometry Study of Copper Adducts of Protonated Ubiquitin
}

\author{
Charles Q. Jiao and Ben S. Freiser \\ Department of Chemistry, Purdue University, West Lafayette, Indiana USA \\ Scott R. Carr and Carolyn J. Cassady \\ Department of Chemistry, Miami University, Oxford, Ohio USA
}

A study of the addition of Cu(II) to a ubiquitin electrospray solution shows that the copper ion in the ubiquitin remains doubly charged and displaces two protons on the protonated protein molecule. This observation indicates a chelating bond between the protein and the $\mathrm{Cu}(\mathrm{II})$ species. The addition of $\mathrm{Cu}(\mathrm{I})$ also was studied and significant intensity was observed for adducts with up to four $\mathrm{Cu}(\mathrm{I})$ species attached, with each $\mathrm{Cu}(\mathrm{I})$ bonded to one basic site on the protein. (J Am Soc Mass Spectrom 1995, 6, 521-524)

\begin{abstract}
S ince its introduction in 1984 [1], electrospray (ESI) rapidly has become one of the prevailing ionization methods for the analysis of large biomolecules by mass spectrometry. This popularity is because ESI produces multiply charged molecular ions, which significantly increase the detectable mass limit and the detection sensitivity. Several methods have been used to assign the charge $(z)$ and mass $(m)$ for peaks from multiply charged ions [2-6], but, although effective, each method has its own limitations [7]. McLafferty's group [7] recently proposed a complementary approach via copper adducts formed simply in the ESI feed solution by mixture with $\mathrm{Cu}$ (II) complexes. The mass-to-charge ratio difference between the adducts and the original ions allows the $z$ values to be obtained. The charge state of the copper ion added to the protein was presumed to be +2 in this study. However, because reduction of metal ions often occurs during the electrospray process [8-11], McLafferty and co-workers [7] could not rule out that the bonded copper ion was actually in the form of $\mathrm{Cu}(\mathrm{I})$.

The addition of $\mathrm{Cu}$ (II) to metal-binding peptides or proteins has been studied previously by Hutchens and co-workers [12-14], and various adduct ions, tentatively assigned as $[\mathrm{M}+x \mathrm{H}+n \mathrm{Cu}-n \mathrm{H}]^{x+}$ [12] or $[\mathrm{M}+x \mathrm{H}+n \mathrm{Cu}-2 n \mathrm{H}]^{x+}[13,14]$ (M represents the peptides or protein), have been reported for different
\end{abstract}

Address reprint requests to Dr. Carolyn J. Cassady, Department of Chemistry, Miami University, Oxford, Ohio 45056. cases. Although a calibration and averaging procedure is used in this work, once again the results were obtained from low resolution data.

This note reports the use of high resolution Fourier transform mass spectrometry (FTMS) to probe the formation of copper adduct ions to ubiquitin, which confirms, in this case, that the copper ion is in the form of $\mathrm{Cu}(\mathrm{II})$. It is found that $\mathrm{Cu}$ (II) replaces two $\mathrm{H}^{+}$, which indicates that two coordinate bonds must be formed between the copper ion and the protein. $\mathrm{Cu}(\mathrm{I})$ addition to the protein solution also is studied and the results will be discussed.

Experiments were performed via a Bruker (Billerica, MA) CMS-47X Fourier transform ion cyclotron resonance (FT-ICR) mass spectrometer [15] equipped with a 4.7-T superconducting magnet and an external ion source. Ions were produced by using an Analytica of Branford (Branford, CT) Ultraspray ${ }^{T M}$ electrospray source mounted in place of the normal electron ionization-chemical ionization source of the FT-ICR [16]. Bovine ubiquitin (MW $=8564.92 \mathrm{u}$ ) was purchased from Fluka Chemical Corporation and used without additional purification. Ions were formed from a solution that contained ubiquitin at $1.2 \times 10^{-5} \mathrm{M}$ in a 49:49:2 mixture (vol\%) of methanol:water:acetic acid. For the formation of copper ion adducts, $\mathrm{CuBr}_{2}$ or $\mathrm{CuCl}$ was dissolved into the solution at a concentration of around $10^{-5} \mathrm{M}$ and introduced into the electrospray source at a flow rate of approximately 2.0 $\mu \mathrm{L} / \mathrm{min}$ via a Cole Palmer syringe pump. The liquid sample flowed through a grounded needle at atmospheric pressure and was electrosprayed across a $5-\mathrm{kV}$ 
potential through a heated $\left(190^{\circ} \mathrm{C}\right)$ carbon dioxide countercurrent of drying gas.

Electrospray of the ubiquitin solution produces multiply protonated ubiquitin ions with a maximum charge state of +13 [16]. When $3 \times 10^{-5} \mathrm{M} \mathrm{CuBr}_{2}$ is added to the solution, adduct ions that contain copper also are observed (along with a reduction in the signalto-noise ratio of the spectrum by about a factor of 10). As an example, Figure 1 shows a mass spectrum in the mass-to-charge ratio region of the +12 charge state. In addition to [ubiquitin $+12 \mathrm{H}]^{12+}$, the presence of $\mathrm{CuBr}_{2}$ yields a new group of peaks centered around $\mathrm{m} / \mathrm{z}$ 719.8. The charge state of this cluster also is assigned to be +12 based on the spacing between the isotopic peaks. From the difference in mass-to-charge ratio between the centers of these two groups of peaks, it is deduced that one copper atom is added to the protein ion.

To determine if this atom is $\mathrm{Cu}$ (I) or $\mathrm{Cu}(\mathrm{II})$, one needs to know the exact mass-to-charge ratio value. However, for high molecular weight ions such as these, the assignment of the monoisotopic peak among the other isotope peaks is not straightforward. We accomplish this assignment by a comparison of the measured isotopic distribution to the theoretical distributions for the two potential product ions. Space-charge effects may distort the isotope intensity profile, which results in less reliable experimental data. However, addition of the copper salts resulted in a drop in the signal-tonoise by a factor of about 10 . Thus, relatively fewer ions were sampled, which minimized problems due to space-charge. On the other hand, a large number of transients (more than 200) were collected to obtain reliable intensities. [Calculations were performed by using a noncommercial software produced by Alan L. Rockwood and Steven L. Van Orden in the laboratory of Richard D. Smith, Pacific Northwest Laboratories/Battelle Northwest.] In the inset of Figure 1, the calculated intensities of the adduct ions [ubiquitin + $11 \mathrm{H}+\mathrm{Cu}]^{12+}$ and [ubiquitin $\left.+10 \mathrm{H}+\mathrm{Cu}\right]^{12+}$ are plotted with the experimental adduct peaks. The general envelope shape (i.e., relative intensities and positions of peaks) of the experimental data most closely matches that of [ubiquitin $+10 \mathrm{H}+\mathrm{Cu}]^{12+}$, which thus indicates $\mathrm{Cu}(\mathrm{II})$. A more quantitative approach also was taken by using a procedure similar to the intensity-weighted molecular weight comparison method [17]. The calculated isotope profile is broad and includes many small peaks where the experimental intensities have rather high uncertainty or are not above the noise. Thus, only the data within a mass-to-charge ratio range in which the experimental intensities can be measured reliably were averaged. Once again, as displayed in Table 1, the theoretical data for [ubiquitin $+10 \mathrm{H}+\mathrm{Cu}]^{12+}$ are in closer agreement to the experimental data than that of [ubiquitin $+11 \mathrm{H}+\mathrm{Cu}]^{12+}$.

In Figure 1, peaks at $m / z \sim 718$ and $\sim 722$ are observed also, and they are tentatively assigned to be [ubiquitin $+11 \mathrm{H}+\mathrm{K}]^{12+}$ and [ubiquitin $+9 \mathrm{H}+$ $\mathrm{Cu}+\mathrm{Na}]^{12+}$, respectively. Because peaks of [ubiquitin $+11 \mathrm{H}+\mathrm{K}]^{12+}$ were not observed in the blank spectrum (without $\mathrm{CuBr}_{2}$ added; data not shown), they are believed to arise from potassium contamination in the salt sample. This leaves open the possibility that the presence of a mixed $\mathrm{K}-\mathrm{Na}$ adduct $(\sim+60 \mathrm{u})$ may skew the $\mathrm{Cu}$ adduct peaks, which favors the $\mathrm{Cu}(\mathrm{II})$ conclusion. For example, a mixture of [ubiquitin $+\mathrm{Cu}$ $+11 \mathrm{H}]^{12+}$ and [ubiquitin $\left.+\mathrm{K}+\mathrm{Na}+10 \mathrm{H}\right]^{12+}$ will
Figure 1. High resolution mass spectrum (in the range of $m / z 712$ to 722 ) acquired from the ubiquitin solution containing $3 \times 10^{-5} \mathrm{M}$ $\mathrm{CuBr}_{2}$. The inset is an enlarged portion of the spectrum that shows the adduct isotope peaks along with the calculated data for [ubiquitin $+10 \mathrm{H}+\mathrm{Cu}]^{12+}$ (filled triangles), [ubiquitin $+11 \mathrm{H}+$ $\mathrm{Cu}]^{12+}$ (filled circles), and $[\text { (ubiquitin }+11 \mathrm{H}+\mathrm{Cu})^{12+}+25 \%$

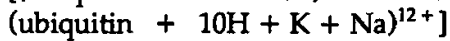
(see the text) (open circles). The intensities of the theoretical data have been scaled to match the maximum theoretical peak with the experimental peak.

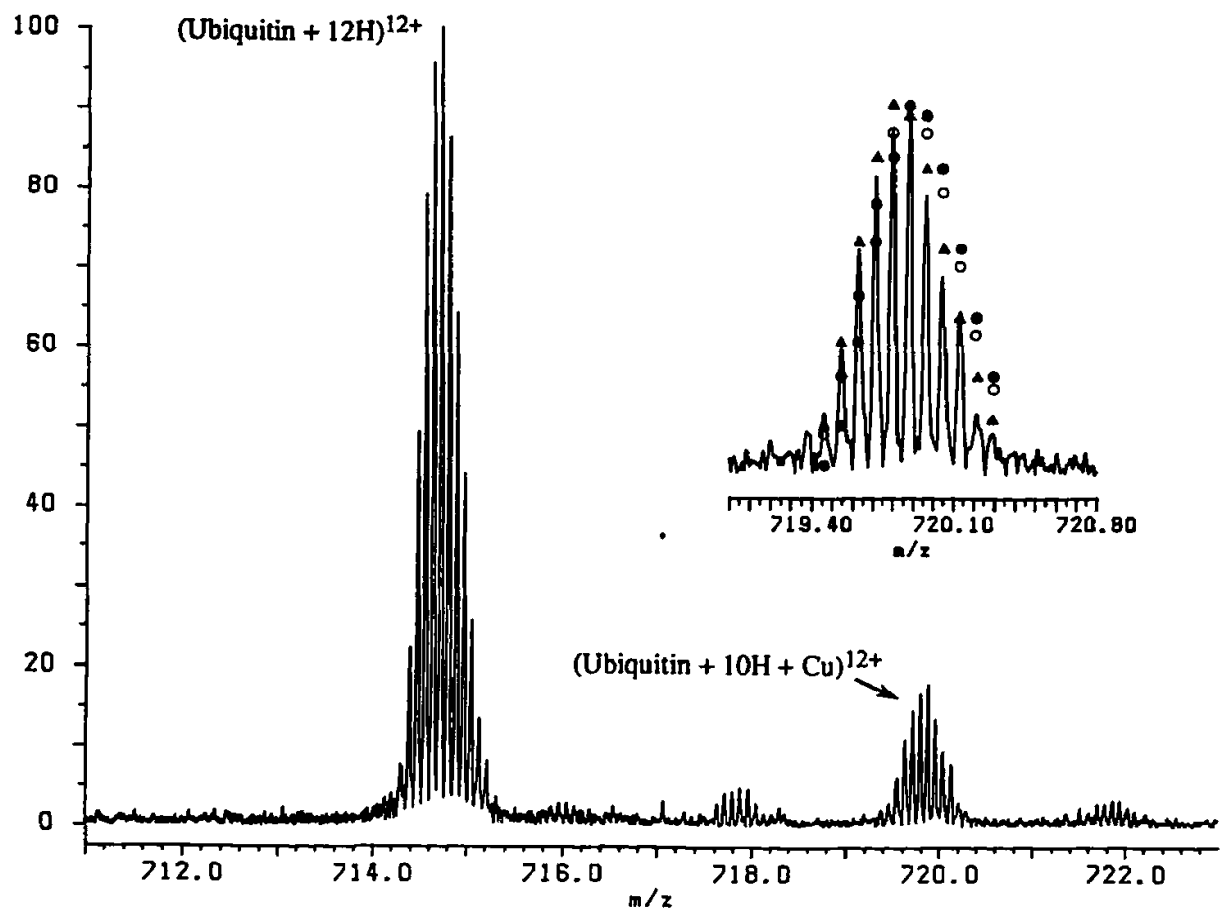


Table 1. Comparison of the experimental and theoretical isotope distribution for the monocopper adduct of ubiquitin in the +12 charge state

\begin{tabular}{|c|c|c|c|c|c|c|c|}
\hline \multicolumn{2}{|c|}{$\begin{array}{l}\text { Experimental data for } \\
\text { [ubiquitin } \\
+n \mathrm{H}+\mathrm{Cu}]^{12+}\end{array}$} & \multicolumn{2}{|c|}{$\begin{array}{c}\text { Theoretical data for } \\
\text { [ubiquitin } \\
+10 \mathrm{H}+\mathrm{Cu}]^{12+}\end{array}$} & \multicolumn{2}{|c|}{$\begin{array}{c}\text { Theoretical data for } \\
\text { [ubiquitin } \\
+11 \mathrm{H}+\mathrm{Cu}]^{12+}\end{array}$} & \multicolumn{2}{|c|}{ 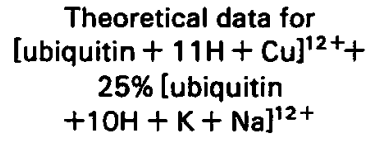 } \\
\hline$m / z^{a}$ & Intensity ${ }^{b}$ & $m / z^{c}$ & Intensity & $n / z^{c}$ & Intensity & $m / z^{c}$ & Intensity \\
\hline 719.4651 & 17 & 719.4689 & 14.0 & 719.4699 & 2.9 & 719.4699 & 11.8 \\
\hline 719.5498 & 34 & 719.5529 & 35.5 & 719.5529 & 14.0 & 719.5539 & 27.5 \\
\hline 719.6327 & 61 & 719.6359 & 63.1 & 719.6359 & 35.5 & 719.6369 & 50.4 \\
\hline 719.7173 & 81 & 719.7199 & 87.4 & 719.7199 & 63.1 & 719.7209 & 74.9 \\
\hline 719.8023 & 93 & 719.8029 & 100 & 719.8039 & 87.4 & 719.8039 & 93.4 \\
\hline 719.8854 & 100 & 719.8869 & 97.7 & 719.8869 & 100 & 719.8869 & 100 \\
\hline 719.9689 & 76 & 719.9699 & 83.4 & 719.9709 & 97.7 & 719.9709 & 93.5 \\
\hline 720.0516 & 54 & 720.0539 & 63.2 & 720.0539 & 83.4 & 720.0539 & 77.5 \\
\hline 720.1376 & 44 & 720.1369 & 43.2 & 720.1379 & 63.2 & 720.1379 & 57.6 \\
\hline 720.2216 & 17 & 720.2209 & 26.9 & 720.2209 & 43.2 & 720.2209 & 38.8 \\
\hline 720.2995 & 11 & 720.3039 & 15.3 & 720.3049 & 26.9 & 720.3049 & 23.9 \\
\hline \multicolumn{2}{|c|}{ Averaged $m / z=719.8538^{d}$} & \multicolumn{2}{|c|}{ Averaged $m / z=719.8664^{d}$} & \multicolumn{2}{|c|}{ Averaged $m / z=719.9373^{d}$} & \multicolumn{2}{|c|}{ Averaged $m / \bar{z}=719.9044^{\mathrm{d}}$} \\
\hline
\end{tabular}

${ }^{a}$ These values have been calibrated against the fully protonated ubiquitin.

'The intensities have been normalized.

'The mass-to-charge ratio values are those at the maxima of the theoretical peaks calculated for the same resolving power as the experimental peaks. For the combination of [(ubiquitin $+11 \mathrm{H}+\mathrm{Cu})^{12+}+25 \%$ (ubiquitin $+1 \mathrm{OH}+\mathrm{K}+\mathrm{Na}$ ) ${ }^{12+}$ ], the theoretical peaks of the two are calculated separately, and added together in the ratio of 1:0.25 at each data point. Then the mass-to-charge ratio values and intensities are recorded at the maxima of the new peaks.

These values do not correspond to the average molecular weight, because only a portion of the isotope peak distribution is averaged (see the text).

give an isotope profile similar to that of [ubiquitin + $\mathrm{Cu}+10 \mathrm{H}]^{12+}$. However, based on the relative intensities of the $\mathrm{K}$ and $\mathrm{Cu}$ adducts, we estimate that the intensity of a mixed $\mathrm{K}-\mathrm{Na}$ adduct should be less than that of the $\mathrm{Cu}-\mathrm{Na}$ adduct. As a worst case scenario, under the assumption that the $\mathrm{K}-\mathrm{Na}$ adduct is the same intensity as the $\mathrm{Cu}-\mathrm{Na}$ adduct or about $25 \%$ of that of [ubiquitin $+\mathrm{Cu}+11 \mathrm{H}]^{12+}$, the theoretical isotope profile for such a mixture still is not in as good agreement with the experimental data as [ubiquitin + $\mathrm{Cu}+10 \mathrm{H}]^{12+}$ (see Figure 1 and Table 1).

In our study, the observation of [ubiquitin $+10 \mathrm{H}+$ $\mathrm{Cu}]^{12+}$ indicates that $\mathrm{Cu}(\mathrm{II})$ is not reduced during its addition to ubiquitin in the ESI process. Analogous adduct ions also are found for other charge states; for example, [ubiquitin $+11 \mathrm{H}+\mathrm{Cu}]^{13+}$ is visible at $m / z$ $\sim 674$. No detectable ubiquitin molecular ion with a +14 charge state that corresponds to [ubiquitin $+12 \mathrm{H}$ $+\mathrm{Cu}]^{14+}$ appears in the spectrum, which suggests that $\mathrm{Cu}^{+2}$ replaces two protons during derivatization and that the protein structure is modified to allow chelation. This situation should be less favorable in cases where denaturing solution conditions are employed (such as low $\mathrm{pH}$ and high percentage of organic solvent, etc. $[18,19]$ to obtain the maximum charge state. Thus, denaturing conditions may have a negative effect on the yield of the $\mathrm{Cu}(\mathrm{II})$ adduct.

One immediate question that arises is whether $\mathrm{Cu}(\mathrm{I})$ also can bind to more than one basic site in the ubiquitin adduct. When $\mathrm{CuCl}$ is added to the sample solution at $\sim 10^{-5} \mathrm{M}$ at the same $\mathrm{pH}$ and organic solvent content as used for $\mathrm{CuBr}_{2}, \mathrm{Cu}(\mathrm{I})$ adducts of the ubiquitin ions can be seen readily. As the concentration of $\mathrm{CuCl}$ is increased, the adduct peaks in the spectrum continue to grow, and multiple $\mathrm{Cu}(\mathrm{I})$ adduct peaks arise (see Figure 2). Further increases to the $\mathrm{CuCl}$ concentration eventually cause loss of the ion signal. $\mathrm{Cu}(\mathrm{I})$ adducts with a maximum charge state of +13 are observed, which clearly indicates that at least for this charge state, $\mathrm{Cu}(\mathrm{I})$ is bound strongly to only one site on the protein molecule.

In summary, the addition of $\mathrm{Cu}(\mathrm{I})$ and $\mathrm{Cu}(\mathrm{II})$ to protonated ubiquitin ions displaces one and two protons, respectively. The charge state of the adduct ions does not increase beyond +13 , which is the maximum charge observed for fully protonated ubiquitin. This observation suggests that the copper atoms bind to the same basic sites on the protein that attached protons. The use of $\mathrm{Cu}(\mathrm{I})$ has a potential advantage over that of $\mathrm{Cu}(\mathrm{II})$ in that the protein molecules are not necessarily required to be folded in a particular way to bind to $\mathrm{Cu}(\mathrm{I})$, which will make the derivatization more facile compared to the use of $\mathrm{Cu}$ (II) in cases where denaturing solution conditions are employed.

\section{Acknowledgment}

CJC and SRC acknowledge financial support from the National Institutes of Health (R15-GM47657-01A1) and the Ohio Academic Challenge Program. CQJ and BSF wish to acknowledge the Divi- 
Figure 2. High resolution mass spectrum acquired from the ubiquitin solution with $\mathrm{CuCl}$ added. The single and multiple $\mathrm{Cu}(\mathrm{I})$ adduct ions are displayed as well as [ubiquitin $+12 \mathrm{H}]^{12+}$.

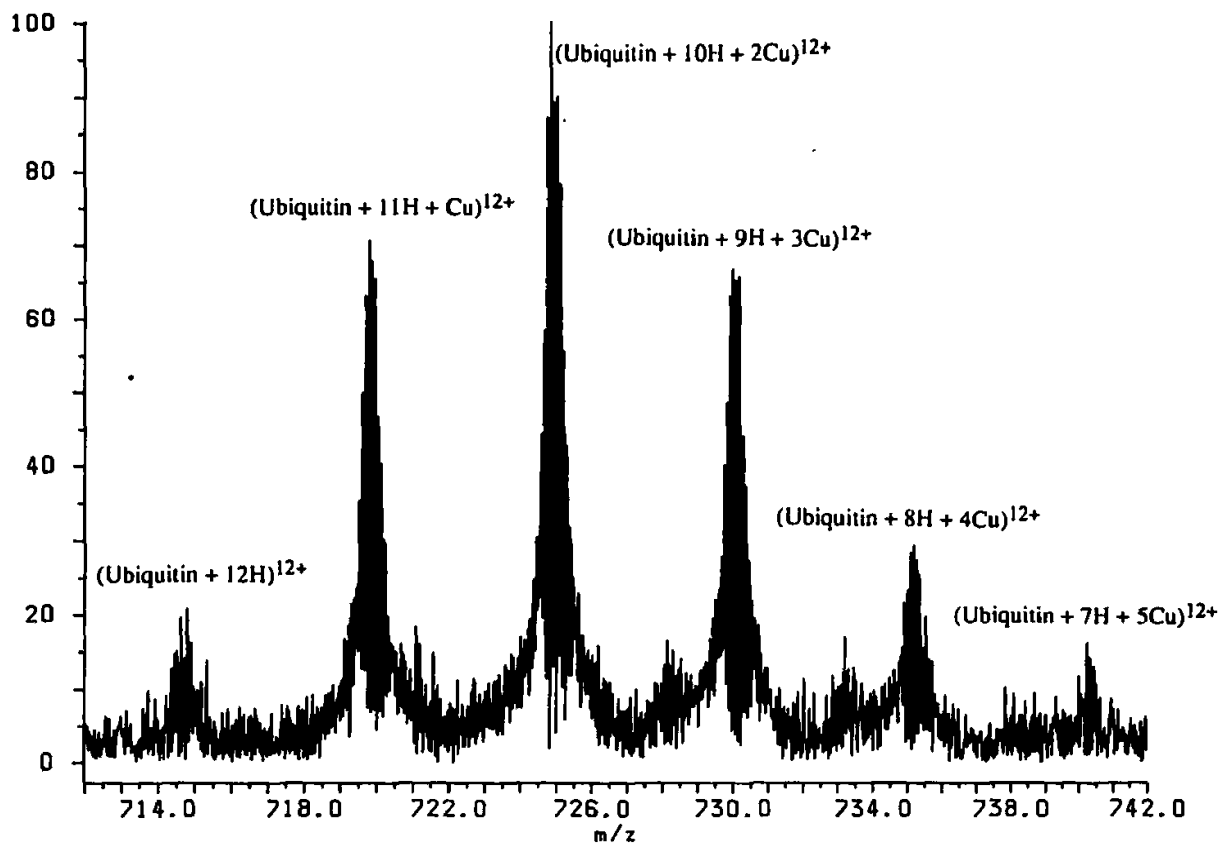

8. Li. T.-T.; Hsieh, Y.-L.; Henion, J. D. J. Am. Soc. Mass Spectrom. 1993, 4, 631.

9. Huggins, T. G.; Henion, J. D. Electrophoresis 1993, 14, 531.

10. Hlades, A. T.; Jayaweera, P.; Ikonomou, M. G.; Kebarle, P. Int. J. Mnss Spectrom. Ion Processes 1990, 102, 251.

11. Gatlin, C. L.; Turecek, F.; Vaisar, T. Anal. Chem. 1994, 66 , 3950.

12. Hutchens, T. W.; Nelson, R. W.; Allen, M. H.; Li, C. M.; Yip, T. Biol. Mass Spectrom. 1992, 21, 151.

13. Hutchens, T. W.; Allen, M. H. Rapid Commun. Mass Spectrom. $1992,6,469$.

14. Hutchens, T. W.; Allen, M. H.; Li, C. M.; Yip. T. FEBS Lett. $1992,309,170$.

15. Kofel, P.; Allemann, M.; Kellerhals, H. P.; Wanczek, K. P. Int. J. Mass Spectrom. Ion Processes 1985, 65, 97.

16. Cassady, C. J.; Wronka, J.; Kruppa, H. G.; Laukien, F. H. Rapid Commun. Mass Spectrom. 1994, 8, 394.

17. Cody, R. B.; Tamura, J.; Musselman, B. D. Annl. Chem. 1992, $64,1561$.

18. Katta, V.; Chait, B. T. Rapid Commun. Mass Spectrom. 1991, 5, 214.

19. Katta, V.; Chait, B. T. I. Ant. Chem. Soc. 1993, 115, 6317. 